difganisations in the profession. It continues to raise awareness and promote the need for dental professionals to update their knowledge and skills, and expand on their experience to deliver the best possible treatment for patients. Our drive to progress cosmetic dentistry is a key contributor to our growth in BACD membership. As a result, we are able to offer even greater value year-on-year.

The BACD is determined to strengthen its current offerings so that members can make the most of their investment. It is keen to continue developing its social and educational programme by offering access to more events, which will provide the chance for members to learn from worldrenowned clinicians. The BACD is also looking to collaborate with other professional organisations from the industry. This is all part of BACD's goal to remain a highly inclusive and innovative community of dental professionals, who are dedicated to upholding uncompromising ethical standards with the utmost integrity and passion.

https://bacd.com/

\title{
US celebrates 75 years of community water fluoridation
}

In commemoration of the seventy-fifth anniversary of community water fluoridation (CWF) in the US, the eight US Public Health Service (USPHS) Chief Dental Officers from 1981 to 2018 have all signed a statement to reaffirm their support and commitment to CWF.

In 1945, the US Surgeon General and the National Institute of Dental Research sponsored the first water fluoridation implementation in Grand Rapids, Michigan, and a study of data from that effort demonstrated a $60 \%$ drop in dental caries among Grand Rapids children after just 11 years. Progress in CWF since then has resulted in fluoridation in 46 of the 50 largest cities in the country and for populations served by community water systems, over $70 \%$ benefit from having optimum levels of fluoride.
The US Centers for Disease Control and Prevention describe CWF as

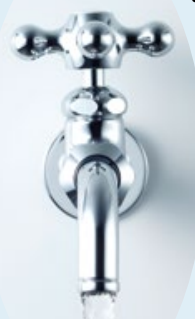

one of ten great public health achievements of the twentieth century.

In 2001, Surgeon General David Satcher, who commissioned the first-ever Surgeon General's Report on Oral Health, stated that 'more than 50 years of scientific

research has found that people living in communities with fluoridated water have healthier teeth and fewer cavities...'

The commemorative statement by the eight Chief Dental Officers, published 7 July 2020, signs off: 'Please join us in resolving to support CWF, one of the greatest public health achievements and a cornerstone to the prevention of dental caries and improvement of both oral health and overall health' 